\title{
Life Cycle assessment of Concentrated Solar Power (CSP) and the influence of hybridising with natural gas.
}

\author{
Blanca Corona, Guillermo San Miguel, Eduardo Cerrajero
}

Universidad Politécnica de Madrid, ETSII, Department of Energy Engineering and Fluid Mechanics, c/ José Gutiérrez Abascal, 2, Madrid, 28006 (Spain).

e-mail: g.sanmiguel@upm.es

\begin{abstract}
Purpose Concentrating Solar Power (CSP) plants based on parabolic troughs utilize auxiliary fuels (usually natural gas) to facilitate start-up operations, avoid freezing of HTF and increase power output. This practice has a significant effect on the environmental performance of the technology. The aim of this paper is to quantify the sustainability of CSP and to analyse how this is affected by hybridisation with different natural gas (NG) inputs.

Methods A complete Life Cycle (LC) inventory was gathered for a commercial wet-cooled 50 MWe CSP plant based on parabolic troughs. A sensitivity analysis was conducted to evaluate the environmental performance of the plant operating with different NG inputs (between 0 and $35 \%$ of gross electricity generation). ReCiPe Europe (H) was used as LCA methodology. CML 2 baseline 2000 World and ReCiPe Europe E were used for comparative purposes. Cumulative Energy Demands (CED) and Energy Payback Times (EPT) were also determined for each scenario.

Results and discussion Operation of CSP using solar energy only produced the following environmental profile: climate change $26.6 \mathrm{~kg} \mathrm{CO} 2 \mathrm{eq} / \mathrm{KWh}$, human toxicity $13.1 \mathrm{~kg}$ 1,4-DB eq/KWh, marine ecotoxicity 276 g 1,4-DB eq/KWh, natural land transformation $0.005 \mathrm{~m}^{2} / \mathrm{KWh}$, eutrophication $10.1 \mathrm{~g} \mathrm{P}$ eq/KWh, acidification $166 \mathrm{~g} \mathrm{SO} 2 \mathrm{eq} / \mathrm{KWh}$. Most of these impacts are associated with extraction of raw materials and manufacturing of plant components. The utilization NG transformed the environmental profile of the technology, placing increasing weight on impacts related to its operation and maintenance. Significantly higher impacts were observed on categories like climate change (311 kg $\mathrm{CO}_{2}$ eq/MWh when using $35 \% \mathrm{NG}$ ), natural land transformation, terrestrial acidification and fossil depletion. Despite its fossil nature, the use of NG had a beneficial effect on other impact categories (human and marine toxicity, freshwater eutrophication and natural land transformation) due to the higher electricity output achieved. The overall environmental performance of CSP significantly deteriorated with the use of NG (single score $3.52 \mathrm{pt}$ in solar only operation compared to $36.1 \mathrm{pt}$ when using $35 \% \mathrm{NG}$ ). Other sustainability parameters like EPT and CED also increased substantially as a result of higher NG inputs. Quasilinear second-degree polynomial relationships were calculated between various environmental performance parameters and NG contributions.

Conclusions Energy input from auxiliary NG determines the environmental profile of the CSP plant. Aggregated analysis shows a deleterious effect on the overall environmental performance of the technology as a result of NG utilization. This is due primarily to higher impacts on environmental categories like climate change, natural land transformation, fossil fuel depletion and terrestrial acidification. NG may be used in a more sustainable and costeffective manner in combined cycle power plants, which achieve higher energy conversion efficiencies.
\end{abstract}

Keywords Life Cycle Assessment, Concentrating Solar Power, parabolic trough, natural gas, hybridisation, energy payback time. 


\section{Introduction}

Sunlight is a freely available and renewable energy resource that can be used to produce electricity in a sustainable and cost-effective manner. The conversion of solar radiation into electricity can be achieved directly by means of photovoltaic panels or indirectly using concentrating solar power (CSP) technologies. In CSP plants, direct solar radiation is concentrated using mirrors or lenses to heat a fluid to very high temperatures, which is subsequently employed to drive a thermodynamic cycle for power generation. Although the contribution of CSP is limited at present, projections from the International Energy Agency (IEA) suggest that these technologies will play a key role in the transformation of the existing energy model, supplying $3.6 \%$ and $11.8 \%$ of the global energy demand in 2030 and 2050, respectively (IEA, 2012). As a result of favourable regulatory frameworks, the CSP industry has grown very rapidly in countries like Spain and the USA, which currently accumulate more than $90 \%$ of the world's installed capacity (NREL 2013; Protermosolar 2013). Spain is expected to have 60 commercial CSP plants in operation by the end of 2013 for a total power capacity of over 3000 MWe (Protermosolar 2013). The European Solar Industry (ESI) estimates that the installed capacity in Europe will reach 30 GWe by 2020 (Jäger-Waldau et al., 2011).

Most commercial CSP plants are based on one of three technologies: parabolic trough systems, power tower systems and dish/engine systems. Parabolic troughs are the most widely deployed, representing over $80 \%$ of the installed capacity worldwide (NREL 2013). Each one of these collectors is made of a set of curved mirrors forming a linear parabolic-shape that reflects the solar radiation into a hollow tube (receiver) that runs along its focal point. The solar field of a CSP plant is made of a series of solar collectors grouped into a series of parallel loops aligned on a north-south horizontal axis to maximize solar collection efficiency. A heat transfer fluid (HTF) consisting of a mixture of thermally stable compounds (usually biphenyl and diphenyl oxide) is circulated through the receiver tube absorbing the solar energy and increasing its temperature from around $295^{\circ} \mathrm{C}$ at the entry to the solar field to around $395^{\circ} \mathrm{C}$. The hot HTF is sent to the power block where a series of heat exchangers are used to transform water into high-pressure superheated steam (usually at around 100 bar and $385^{\circ} \mathrm{C}$ ). The steam feeds a steam turbine/generator for power generation. The thermodynamic cycle is closed with a condenser that transforms the spent steam into water. In order to increase its capacity factor and improve power dispatchability, modern CSP plants incorporate Thermal Energy Storage (TES) systems based on molten nitrate salt mixtures. These systems store some of the thermal energy generated during the day to produce additional electricity during the night. In addition, commercial CSP plants also incorporate a series of auxiliary boilers that are used to supplement the solar input during the night and during transient periods of low solar radiation. This auxiliary energy is also required to avoid freezing of the HTF during the night and to facilitate daily startup operations (Palgrave 2008; Giostri et al. 2012).

The minimum amount of backup energy required to operate a commercial CSP installation depends primarily on the ambient temperature at night, the viscosity of the HTF at low temperatures, the size of the plant and its capacity factor. In parabolic trough installations, this minimum requirement typically ranges between 100,000-130,000 MJ/MW/yr. For a $50 \mathrm{MWe}$ plant like the one investigated in this paper, this value is equivalent to $5.0-6.5 \cdot 10^{6} \mathrm{MJ} / \mathrm{yr}$. Due to its low cost, clean combustion and rapid response, this energy requirement is usually met by combustion of Natural Gas (NG) in an auxiliary 5-10 $\mathrm{MW}_{\text {th }}$ boiler that heats the HTF at the exit of the solar field. However, other fossil and renewable fuels like fuel oil, coal and biomass may also be used for this purpose. This energy input does not have a net contribution to electricity generation.

However, most commercial CSP plants utilize higher auxiliary energy inputs, depending on regulatory requirements and permissions. For instance, the Spanish legislation regulating the generation of electricity from renewable resources that led to the recent upsurge in this technology (Royal Decree 661/2007) allowed CSP plants to produce up to $12 \%$ of their gross electricity output from auxiliary fuels. This additional electricity also benefits from the $26.9 \mathrm{c} € / \mathrm{kWh}$ feed-in tariff established for solar thermal power (note that these incentives have been updated annually for existing installations and were temporarily removed for new installations as a result of the enactment in January 2012 of Royal Decree 1/2012). For a typical $50 \mathrm{MWe}$ installation, this additional electricity output requires the consumption of $2.32 \cdot 10^{8} \mathrm{MJ} / \mathrm{yr}$ of auxiliary fuel, on top of the minimum maintenance provisions. The consumption of this auxiliary fuel requires the installation of additional boilers that provide supplementary heat to the HTF in order to achieve longer equivalent hours of full load operation. The thermal efficiency of the steam cycle in the CSP plant, usually between 30-35 \%, also applies to the transformation of this auxiliary fuel into electricity. This is much lower than the 50-55 \% efficiency achieved in the transformation of NG using combined cycle power plants. 
LCA methodology is an appropriate way to evaluate the environmental performance of renewable technologies, as have been proven in scientific literature (Davidsson et al., 2012; Emmenegger et al., 2012; Suwanit and Gheewala, 2011)

The environmental performance of CSP plants based on parabolic through technology has been investigated by various authors using Life Cycle Assessments (LCA) methodology (Weinrebe et al. 1998; Lechon et al. 2008; Piemonte et al. 2011; Burkhardt et al. 2011 and 2012; Oró et al., 2012). The results show significant discrepancies in the impacts estimated for different environmental categories, which has been associated with various issues like: the scale and geographical location of the installations, characteristics of the plant and TES, and the LCA methodology employed in the calculations (CML, Eco-Indicator, ReCiPe). These studies suggest that consumption of auxiliary fuel also has a significant effect on the environmental performance of the plant, particularly with regards to greenhouse gas emissions. Reported global warming emissions in CSP plants based on parabolic through ranged between $26 \mathrm{~g} \mathrm{CO}_{2} / \mathrm{kWh}$ in solaronly operation (Burkhardt et al. 2011; Burkhardt et al. 2012) to between 185 and $234 \mathrm{~g} \mathrm{CO}_{2}$ eq/kWh when hybridising with 15 and $25 \%$ NG, respectively (Lechon et al. 2008; Weinrebe et al. 1998). Impact values in other categories varied as follows: terrestrial acidification (253-590 $\mathrm{g} \mathrm{SO}_{2} \mathrm{eq} / \mathrm{MWh}$ ); eutrophication (25-45 $\mathrm{g} \mathrm{PO}_{4}{ }^{3-} / \mathrm{MWh}$ ) (Lechon et al. 2008; Piemonte et al. 2011).

The aim of this paper is to investigate the environmental performance of a commercial CSP plant using Life Cycle Analysis (LCA) methodology and to provide a sensitivity assessment on the consequences of hybridising with increasing NG inputs (up to $35 \%$ of gross power generation). The life cycle inventory of the commercial 50 MWe CSP plant in which this analysis is based is also provided as supporting information.

\section{Methods}

\subsection{Scope and methodology}

The LCA was conducted according to standard methods ISO 14040:2006 and ISO 14044: 2006. The objectives set in this study were as follows: to evaluate the environmental performance of a commercial CSP plant operating with solar energy (100\% solar fraction); to perform a sensitivity analysis on the effect of hybridizing CSP with different energy inputs from NG; to evaluate the effect of hybridization with NG on other sustainability parameters (CED and EPT); and to determine the effect of using different LCA methodologies in the estimation of the environmental performance.

The analysis was based on a comprehensive inventory covering the following life cycle phases: acquisition of raw materials, manufacturing of plant elements and transportation, construction of CSP plant, operation and maintenance, dismantling, and waste management. The functional unit used as a reference was 1.0 MWh.

Figure 1 shows a simplified life cycle diagram of the CSP plant under investigation. The life cycle inventory considered the following elements of the technology:

- HTF system: synthetic oil, piping, nitrogen production system.

- Solar field: EUROtrough solar collectors (frame, mirrors, foundations), sun tracking systems, controls, vehicle for washing collectors.

- Thermal storage: piping, tanks, foundations, insulation, heat exchangers, nitrate salts.

- Power block: components of the steam cycle including boiler, superheater, steam turbine, condenser, deaerator and feed pump.

- Auxiliary facilities: office buildings, roads, deionization water treatment plant.

Impact estimations for these components take into consideration extraction of raw materials, manufacturing and transportation to the plant, and waste management at the end of their lives. Unless otherwise indicated, the information employed in this study was obtained directly from engineers specialized in this technology using as a reference a wetcooled 50 MWe CSP plant with 7.5 hours TES located in Ciudad Real (Castilla La Mancha, Spain).

\section{Figure 1 Simplified flow chart describing the Life Cycle of Concentrating Solar Power technology}

No inventory data was available for raw materials and manufacturing in the following elements: feed pumps employed in the HTF circuit and the thermal storage system; foundations for auxiliary boilers and TES; water treatment for power block refrigerating water. The following information was obtained from the scientific literature: inventory data for a generic office building (Xing et al., 2008); inventory data for consumption of electricity and fuel during 
dismantling, and materials for sun tracking system (Burkhardt et al. 2012, Lechon et al. 2008). The waste management scenario considered (40\% recycling, $30 \%$ landfill, $30 \%$ materials recovery) is based on information from the Spanish National Plan for Management of Construction and Demolition Waste (MMA, 2009).

EcoInvent v. 2.2 was used to obtain environmental information regarding: raw materials employed in the construction, operation and maintenance of the CSP plant, manufacturing and construction of power block, and the production of deionized water used in the power cycle. The information in Ecoinvent v. 2.2 regarding the power block refers to a $100 \mathrm{MWe}$ installation. To adapt this data to the requirements of our $50 \mathrm{MWe}$ model, a conversion factor of 0.625 was applied for the consumption of raw materials. This factor was estimated assuming a direct relationship between the power capacity of the power block and the volume of its components, and a square relationship between the capacity of these components and the mass of raw materials involved in their construction.

The impacts associated with the consumption of NG were also obtained from Ecoinvent v.2.2. The information was adapted to the specific import mix of this resource for Spain in 2012 (CORES 2013) as follows: Algeria $69 \%$, Nigeria $16 \%$, Norway $10.9 \%$ and Netherlands $3.9 \%$. The data includes the impacts from extraction/upgrading of NG, transportation to Europe and distribution in Spain to the CSP plant using the national gas network.

SimaPro 7.3® software was used for calculations. Unless otherwise indicated, ReCiPe (Midpoint/Endpoint) Europe (H perspective) method was used for the evaluation of the environmental impacts (Goedkoop et al. 2009). In addition, CML 2 baseline 2000 World, (1995) and ReCiPe Midpoint Europe E perspective were used for comparative purposes. Cumulative Energy Demand (CED) describes the primary energy consumed throughout the LC of the technology. CEDs were determined for different scenarios using CED v 1.08 methodology. Energy Payback Time (EPT) describes the time (months) required by the CSP plant to generate (as net electricity output) the primary energy consumed in the construction (including extraction of raw materials and manufacturing of plant elements) and dismantling of the installation. EPTs were determined for different operating scenarios using equation (1) described by Lechon et al. (2008):

$$
E P T(y r)=\frac{C E D_{c}}{\left(\frac{E_{n e t}}{g}-C E D_{o}\right)}
$$

$\mathrm{E}_{\text {net }}$ represents the yearly net electricity output of the plant (in MJ/yr), CEDc is the cumulative primary energy demand associated with extraction, manufacturing, construction and dismantling of the CSP plant (in MJ), and CEDo the cumulative primary energy demand associated with operation and maintenance (in $\mathrm{MJ} / \mathrm{yr}$ ). $g$, which represents the average efficiency in the transformation of primary energy to electricity, has been calculated to be $48.74 \%$, using data from the Spanish National Energy Report for 2011 (MINETUR, 2012).

\subsection{Description of the CSP plant}

As shown in Table 1 and 2, the system under investigation is a commercial wet-cooled 50 MWe CSP plant. The installation uses synthetic oil as HTF and incorporates a 7.5 hour molten salt TES based on two tank configuration. The plant allows 2,800 h/yr of full load operation when operated using solar energy only for a gross electricity output of $165,687 \mathrm{MWh} / \mathrm{yr}$. Sixteen percent of this electricity is consumed onsite for operation and maintenance. Transformation of thermal energy into electricity is performed using a conventional steam cycle with an estimated thermal efficiency $\eta$ $=35 \%$. The solar field consists of 156 loops, each one containing 4 Solar Collector Assemblies (SCAs) for a total length of $89 \mathrm{~km}$ and an aperture area of $510,120 \mathrm{~m}^{2}$. Each SCA is made of 12 EURO trough modules. The CSP installation occupies 200 ha of non-productive rural land and its lifetime expectancy is 25 years.

\section{Table 1: General characteristics of the CSP plant under investigation}

A sensitivity analysis has been performed to investigate the environmental consequences of operating the plant with different auxiliary energy inputs in the form of NG. As shown in Table 2, the installation requires a minimum consumption of auxiliary energy $\left(6.28 \cdot 10^{6} \mathrm{MJ} / \mathrm{yr}\right)$ that is used in start-up operations and maintenance (mainly circulation and heating of HTF during the night). This energy input does not contribute to electricity generation. In addition, the installation may consume additional energy from NG to operate in hybrid mode. The typical scenario in CSP plants in Spain refers to $12 \%$ of their gross electricity obtained from the combustion of NG (as permitted by national legislation). 
To have a more comprehensive analysis of the situation, the scenarios investigated in this paper range from 0 to $35 \%$ NG inputs. Table 2 provides information about the consumption of NG in each scenario (in $\mathrm{Nm}^{3} / \mathrm{yr}$ ) assuming a net calorific value of the fuel as $39.0 \mathrm{MJ} / \mathrm{Nm}^{3}$, the thermal efficiency of the cycle as $35 \%$ and the auxiliary boiler efficiency as $95 \%$. The only difference regarding the configuration of the CSP operating with different NG inputs relates to the incorporation of auxiliary gas boilers in the HTF system. One $10 \mathrm{MWth}$ auxiliary boiler is always required in the plant for maintenance and start-up operations. Additional $20 \mathrm{MWth}$ boilers need to be incorporated depending on the NG input, as shown in Table 2. The impact associated with the LC of each boiler has been included into the inventory of the plant as required.

Hybridisation with NG has a direct effect on the number of operating hours of the CSP plant, while the power capacity $(50 \mathrm{MWe})$ remains unaffected. Table 2 shows an increase in full load equivalent hours from $2800 \mathrm{~h} / \mathrm{yr}$ when using solar energy only to $4290 \mathrm{~h} / \mathrm{yr}$ when hybridizing with $35 \% \mathrm{NG}$. As a result, power generation increased from $165,687 \mathrm{MWh} / \mathrm{yr}$ to 254,903 MWh/yr, respectively. The model assumes that the plant consumes onsite the equivalent of $16 \%$ of its gross electricity output. Most of this electricity is generated by the CSP plant itself while a small fraction (550 MWh/yr) is obtained from the grid during non-productive hours (night and morning start-up operations). Net electricity generation values may be calculated in each scenario by subtracting onsite power consumption from the gross electricity output.

A linear relationship has been assumed between raw water consumption and power generation in the CSP plant. Consequently, increasing power generation as a result of hybridisation with NG involves higher direct water consumption, as a result of higher requirements in the power block (including refrigerating and power cycle water).

Table 2: Characteristics of the CSP plant operating with different auxiliary (NG) energy inputs

\section{Results and discussion}

\subsection{Environmental performance of the CSP plant operating on solar energy only}

Table 3 shows the impacts associated with the generation of a functional unit of electricity (1 MWh) when the CSP installation was operated using solar energy only. The results are limited to the eight midpoint categories that have been detected to be the most relevant for this technology, according to a screening LCA performed previously and also to scientific literature (Lechon et al. 2008, Piemonte et al. 2011). The impacts for the entire LC of the technology were as follows: climate change $26.6 \mathrm{~kg} \mathrm{CO} 2 \mathrm{eq} / \mathrm{MWh}$, human toxicity $13.1 \mathrm{~kg}$ 1,4-DB eq/MWh, marine ecotoxicity $276 \mathrm{~g} 1,4-$ $\mathrm{DB}$ eq/MWh, terrestrial acidification $166 \mathrm{~g} \mathrm{SO}_{2} \mathrm{eq} / \mathrm{MWh}$, natural land transformation $0.005 \mathrm{~m} 2 / \mathrm{MWh}$, eutrophication $10.1 \mathrm{~g} \mathrm{P}$ eq/MWh, fossil depletion $9.29 \mathrm{Kg}$ oil eq/MWh.

\section{Table 3: Characterized impacts in different LC phases of the CSP plant operating on solar energy only}

The results show that environmental damage in all categories, except water depletion, is attributable primarily to extraction of raw materials and manufacturing (E\&M), while the contribution of other life cycle phases (construction: C; operation and maintenance: O\&M; dismantling and disposal: D\&D) is limited. In particular, $79.3 \%$ of the emissions associated with climate change derive from E\&M, while O\&M contributes to only $17.4 \%$ of the total. The impact estimated for the LC of CSP in this category (26.6 kg CO2 eq/MWh) is very similar to those published by other authors (Burkhardt et al., 2011 and 2012).

Unlike all other categories, water depletion is primarily affected by LC elements belonging to O\&M of the CPS plant. The results in Table 2 show that the generation of $1 \mathrm{MWh}$ of electricity involves the depletion of $6.27 \mathrm{~m}^{3}$ of water. Most of this impact is attributable to water consumption in the power block ( $80 \%$ refrigerating water, $1.2 \%$ power cycle water), while a smaller proportion is associated with cleaning of solar collectors $(0.6 \%)$. Indirect water depletion associated with other phases in the LC of the technology contributes to the remaining $18.2 \%$ of the impact in this category.

The normalised results in Figure 2 confirm that E\&M generates most of the environmental damage when the CSP plant is operated using solar energy only. The most impacted category in this LC phase (and also in the whole LC) is marine ecotoxicity, followed by human toxicity, natural land transformation and freshwater eutrophication. Impact on 
marine ecotoxicity is associated primarily with the use of reinforcing steel in various elements of the plant (representing $33 \%$ of the impact in this category), the utilization of copper in the TES and power block (17\%), the use of chromium steel in the solar field $(12 \%)$ and the production of the HTF $(8 \%)$. The normalised impacts on other environmental categories like climate change and fossil depletion are significantly lower.

O\&M is the second most damaging LC phase in the normalised analysis, primarily as a result of negative impact on natural land transformation. O\&M phase contributes to $17 \%$ of the impact on this category (natural land transformation), mainly as a result of NG utilization and, to a lower extent, grid electricity, both employed for maintenance and start-up operations.

An even lower impact contribution was associated with other life cycle stages like C and D\&D. The benefits associated with recycling of components at the end of the useful life of the plant are very limited.

Figure 2 Normalised analysis of the environmental performance of the CSP plant in solar-only operation

\subsection{Comparative analysis of LCA methods in the environmental assessment of CSP}

Discrepancies in the quantification of the environmental performance of this technology may be attributed, to some extent, to differences in the LCA methods employed. Figure 3 shows the characterized profiles of the CSP plant operating with solar energy only when using three different LCA characterisation methods: ReCiPe Midpoint Europe (E and H perspective) and CML2 baseline 2000. The results show that the three methods produced comparable results in two of the environmental categories analysed (climate change and terrestrial acidification), with variations not exceeding $15 \%$ from each other. However, ReCiPe (E) produced significantly higher values than $\mathrm{ReCiPe}(\mathrm{H})$ in other categories like marine ecotoxicity and human toxicity. This has been associated with the longer time-frames accounted for and the less conservative definition of impacts assumed in the former. CML2 produced significantly higher impact values than both ReCiPe methods primarily in the marine ecotoxicity category but also in fresh water eutrophication.

\section{Figure 3 Characterised impacts of the CSP plant operating in solar only mode using three different LCA methods: ReCiPe Midpoint Europe (E and H perspective) and CML2 baseline 2000}

\subsection{Sensitivity analysis of using different NG inputs in the CSP plant}

Table 4 shows the environmental consequences of hybridising CSP with different NG inputs (contributing to between 0 and $35 \%$ of the gross electricity generation). The results show higher impacts on four of the environmental categories investigated: climate change, terrestrial acidification, natural land transformation and fossil depletion. For instance, impacts on climate change and natural land transformation were more than ten times higher $(311 \mathrm{~kg} \mathrm{CO} 2 \mathrm{eq} / \mathrm{MWh}$ and $0.05 \mathrm{~m}^{2} / \mathrm{MWh}$, respectively) as a result of hybridising CSP with $35 \% \mathrm{NG}$ (compared with solar only operation).

\section{Table 4 Characterised impacts of the CSP technology operating with different NG energy inputs}

However, the opposite was observed in other impact categories (human toxicity, freshwater eutrophication, marine ecotoxicity), where higher NG consumption involved reduced damage per functional unit. Impact on these categories is related primarily to the extraction of raw materials and manufacturing of components (E\&M). Higher consumption of NG involves higher electricity output and, therefore, reduced contribution of impacts per functional unit to the overall life cycle of the technology.

Impact on the water depletion category (per unit of electricity generated) was essentially unaffected as a result of hybridisation of CSP with NG. However, it should be noted that the higher electricity outputs achieved when using NG require the consequently greater water consumptions for maintenance and operation activities (as described in Table 2).

Figure 4 shows the normalized impacts in selected categories for different NG inputs. As in Table 4, the results show that increasing NG use results in a marked increase on certain impact categories (climate change, terrestrial acidification, natural land transformation, fossil depletion). Consumption of NG in the CSP plant operating with solar energy only contributes to only $10 \%$ of the impact on natural land transformation and $12 \%$ of the impact on climate change. These contributions rise to $94 \%$ and $95 \%$, respectively, when the installation operated in hybrid mode with $35 \%$ NG input. 
However, it is remarkable that hybridisation with NG reduced environmental damage on others environmental categories like human toxicity, freshwater eutrophication, marine ecotoxicity. This is so despite a significant increase in the contribution of NG to these indicators (e.g. human toxicity from $0.17 \%$ to $20 \%$ when using $35 \%$ NG). The detrimental effect of NG is compensated with a higher power output when the plant operated in hybrid mode.

Normalisation according to ReCiPe Europe H perspective shows that the impacts on the categories benefited by the use of NG have a much lower significance than the impacts on the categories negatively affected by hybridisation. For instance, the normalised impact on natural land transformation (up to $0.31 \mathrm{pt}$ ) and fossil depletion (0.075 pt) have a much higher significance than the impact on other categories (all below $0.03 \mathrm{pt}$ ). In addition, the extent of the environmental benefits appears to be less significant than the magnitude of the deleterious effects.

\section{Figure 4. Normalized impacts on selected categories determined for different NG inputs (\% of gross electricity output) in the CSP plant}

Normalised values in water depletion category remained rather constant regardless of NG consumption.

ReCiPe Endpoint Europe $H$ methodology was used to aggregate all impacts into three categories (Resources, Ecosystems and Human health). Figure 5 provides a damage oriented estimation of the detrimental effect of CSP operating with different NG inputs. Despite the reduced impact on certain midpoint categories, the Single Score value shows a significant deterioration in the environmental performance of the CSP plant as a result of increasing consumption of NG. The Resources category was the most negatively affected by the use of NG, although the other two were also impacted. The aggregated Single Score of the CSP plant operating with solar energy alone was very low (3.52 pt) and increased significantly even when using reduced NG inputs (7.38 pt with $5 \%$ gross electricity output from NG). A tenfold deterioration of the environmental performance was calculated (36.1 pt) when using $35 \%$ NG input.

\section{Figure 5. Single Score impact values of CSP technology operating with different NG inputs.}

Figure 6 shows the regression curves describing the environmental performance of the CSP plant hybridised with different NG inputs. The relationship established for selected impact categories are as follows, where $\mathrm{x}$ represents percentage $(\%)$ of gross electricity output produced from NG:

$\begin{array}{lll}\text { Climate change: } & \mathrm{y}(\mathrm{kg} \mathrm{CO} 2 \mathrm{eq} / \mathrm{MWh})=0.917 \mathrm{x}^{2}+811 \mathrm{x}+26.6 & \mathrm{r}^{2}=1.00 \\ \text { Marine ecotoxicity: } & \mathrm{y}(\mathrm{g} 1.4-\mathrm{DB} \text { eq/MWh })=-16.1 \mathrm{x}^{2}+88.5 \mathrm{x}+276 & \mathrm{r}^{2}=1.00 \\ \text { Human toxicity: } & \mathrm{y}(\mathrm{g} 1.4-\mathrm{DB} \text { eq/MWh })=-0.695 \mathrm{x}^{2}-6.55 \mathrm{x}+13.1 & \mathrm{r}^{2}=1.00 \\ \text { Water depletion : } & \mathrm{y}\left(\mathrm{m}^{3} / \mathrm{MWh}\right)=-0.102 \mathrm{x}+6.27 & \mathrm{r}^{2}=1.00 \\ \text { Single Score endpoint: } & \mathrm{y}(\mathrm{g} 1.4-\mathrm{DB} \text { eq/MWh })=34.3 \mathrm{x}^{2}+69.0 \mathrm{x}+3.73 & \mathrm{r}^{2}=1.00\end{array}$

The results show a quasilinear second-degree polynomial relationship between NG consumption and environmental impact in all categories except water depletion. The constant coefficients in the polynomial equations represent the impact value in solar-only operation of the CSP plant.

\section{Figure 6: Regression curves describing the relationship between NG consumption (\% of gross power generation) and environmental impact in selected categories.}

It may be argued that Combined Cycle (CC) power plants may transform NG into electricity more efficiently $(\eta=50$ $55 \%)$ than single steam cycles like the ones employed in CSP $(\eta=35 \%)$. However, the results show that the environmental burden associated with this lower efficiency is compensated by the use of solar radiation. For instance, LC greenhouse gas emissions in conventional NG SC (single cycle with 35\% of efficiency) have been reported to be 610-850 kg CO 2 eq/MWh (Turconi et al. 2013), and NG CC ones have been reported to range between $488 \mathrm{~kg} \mathrm{CO}_{2}$ eq/MWh in a $500 \mathrm{MW}$ power plant (Odeh and Cockerill, 2008) and $474 \mathrm{~kg} \mathrm{CO}$ eq/MWh in a $367.5 \mathrm{MW}$ power plant (Kannan et al., 2005). Based on equation (2), similar greenhouse gas emissions (per functional unit) would be equivalent to hybridise CSP with 72-101\% of NG (compared to NG SC) and 57-55\% for NG CC. However, the economic cost of this latter alternatives would be significantly higher. 


\subsection{Cumulative Energy Demands (CED) and Energy Payback Times (EPT)}

The Cumulative Primary Energy Demand (CED) of the CSP plant operating with solar energy only was calculated to be $1.15 \mathrm{MJ} / \mathrm{kWh}$. In these operating conditions, the yearly net electricity output $\left(\mathrm{E}_{\mathrm{net}}\right)$ of the installation was 139,725 $\mathrm{MWh} / \mathrm{yr}$, for a total life cycle output (25 years) of $3.49 \cdot 10^{6} \mathrm{MWh}$. The Cumulative Energy Demand associated with manufacturing, construction and operation (CEDc) and the Cumulative Energy Demand associated with operation and maintenance (CEDo) were calculated to be $1.32 \cdot 10^{9} \mathrm{MJ}$ and $1.08 \cdot 10^{8} \mathrm{MJ} / \mathrm{yr}$ respectively. Based on these values, the Energy Payback Time (EPT) of the CSP plant operating with solar energy only was 17.1 months.

Figure 7.a shows a simple representation of the energy flow of CSP operating with solar energy only. The analysis shows that the consumption of external energy (considering the entire life cycle of the technology) represents $11 \%$ of all the net electricity generated. Extraction and Manufacturing (E\&M) is the most energy intensive phase ( $8.5 \%)$ due to energy use associated with extraction of raw materials involved in the construction of the plant. This is followed by O\&M (1.8 $\%)$ mainly due to consumption of NG for maintenance and start-up operations. Consumption of external energy in the construction (C) and Dismantling and Decommissioning (D\&D) phases is very limited (below $0.5 \%$ ). Since $16 \%$ of the gross electricity output is consumed onsite, it may be calculated that the overall CED associated with O\&M represents $(16.0+1.8=) 17.8 \%$ of the gross electricity output of the plant. The global balance of the CSP plant (as $\mathrm{CED}$ ) amounts to $1.15 \mathrm{MJ}$ of primary energy consumed per $\mathrm{kWh}$ of net electricity poured into the network.

\section{Figure 7. a) Energy flow analysis of the CSP plant operating in solar only mode. b) Energy flow analysis of the CSP plant operating with $35 \%$ of NG input.}

For comparative purposes, Figure 7.b shows the energy flow of CSP operating with 35\% of hybridisation. In this case, the consumption of external energy is higher than the electricity generated (124\%). The overall CED associated with the O\&M phase represents $134 \%$ of the gross electricity output of the plant.

Table 5 shows the evolution in various energy parameters (CED, CEDo, CEDc, yearly Enet, LC Enet and EPT) in CSP as a result of using increasing energy inputs from NG. Hybridisation with NG results in higher LC Enet and yearly Enet values. The amount of additional electricity may be readily calculated considering the NG input considered in each scenario, its heating value $\left(39.0 \mathrm{MJ} / \mathrm{Nm}^{3}\right)$, and the thermal efficiency of the steam cycle $(35 \%)$ and the auxiliary boiler (95\%). It may be argued that NG can be transformed into electricity more efficiently in a combined cycle (up to 55-60 $\%)$ power plant. This higher efficiency will contribute to improved environmental performance and, in the absence of subsidies, higher revenues.

The incorporation of additional gas boilers required to operate the CSP plant in hybrid mode (up to 6 units with total capacity $120 \mathrm{MWth}$ ) has a limited contribution to the CEDc of the plant (3.7\% higher in the CSP plant designed to operate with $35 \% \mathrm{NG}$ input compared to solar only operation).

As shown in Table 5, the utilization of increasing NG inputs has a significant effect on the CED of the technology, due to increased CEDo (1.15 MJ/KWh in solar only and $5.92 \mathrm{MJ} / \mathrm{KWh}$ with $35 \% \mathrm{NG}$ input). As a result, hybridisation with increasing amounts of NG results in progressively higher EPT values (from 17.1 months in solar only scenario to 41.2 months when using $35 \% \mathrm{NG}$ input). Quasilinear second-degree polynomial relationships were observed between the energy factors (CEDo and EPT) and the NG inputs, where x represents \% of gross electricity output from NG:

Energy Payback Time:

$$
\begin{array}{ll}
y(\text { months })=0.0396 x^{2}-0.786 x+17.2 & r^{2}=0.994 \\
y(M W h / y r)=2430 x^{2}-21500 x+21700 & r^{2}=1.000
\end{array}
$$

Table 5 Evolution of energy parameters in CSP hybridized with different NG inputs

\section{Conclusions}

- The environmental performance of a $50 \mathrm{MWe}$ commercial CSP plant based on parabolic though technology (wetcooled, $7.5 \mathrm{~h}$ molten salt TES) using solar energy only may be resumed as follows (according to ReCiPe Midpoint Europe $\mathrm{H}$ and Cumulative Energy Demand v 1.08): climate change $26.6 \mathrm{~kg} \mathrm{CO} 2$ eq $/ \mathrm{MWh}$, water depletion 6.27 $\mathrm{m}^{3} / \mathrm{MWh}$, CEDo $1.15 \mathrm{MJ} / \mathrm{kWh}$ and EPT 17.1 months. In this scenario, extraction of raw materials and 
manufacturing of components are the most impacting phases in the LC of the technology. The most affected impact categories in this scenario include marine ecotoxicity, human toxicity, freshwater eutrophication and to a lesser extent, natural land transformation.

- $\quad$ Different LC methods (ReCiPe Europe E and H perspective; CML 2 baseline 2000 World) produced significantly dissimilar results in the estimation of the environmental performance of the CSP plant. These variations were less significant in some midpoint impact categories like climate change and acidification but were very substantial in the case of human toxicity, marine ecotoxicity and freshwater eutrophication.

- Hybridising CSP with increasing NG inputs leads to rapid deterioration in certain environmental categories like climate change, natural land transformation and fossil depletion (up to $311 \mathrm{~kg} \mathrm{CO}_{2} \mathrm{eq} / \mathrm{MWh}, 5.01 \mathrm{E}-02 \mathrm{~m}^{2} / \mathrm{MWh}$, $123 \mathrm{~kg}$ oil eq/MWh, respectively when using $35 \% \mathrm{NG}$ input). However, damage to other impact categories such as human toxicity, marine ecotoxicity and freshwater eutrophication were slightly reduced as a result of higher net electricity outputs. Water depletion (per KWh) was essentially unaffected by hybridisation with NG, although overall water consumption of the plant increased as a result of higher electricity output. Quasilinear second degree polynomial relationships have been determined between impact values in certain environmental categories and NG inputs in CSP technology.

- Weighted Single score analysis shows a significant deterioration in the overall environmental performance of the CSP technology as a result of hybridising with increasing NG inputs. For instance, the single score of CSP operating with solar energy only was very low (3.52 pt) but increased to $7.38 \mathrm{pt}$ and $36.1 \mathrm{pt}$ when using $5 \%$ and $35 \% \mathrm{NG}$ input, respectively.

- The cumulative primary energy demand (CED) associated with CSP was $1.15 \mathrm{MJ} / \mathrm{kWh}$. The Energy Payback Time (EPT) was calculated to be 17.1 months. CEDo and EPT increased significantly as a result of hybridising with increasing NG inputs (5.92 MJ/KWh and 43.1 months, respectively, when using $35 \% \mathrm{NG}$ ).

- The efficiency of transforming NG into electricity in a CSP plant is limited (35\% steam cycle plus $95 \%$ auxiliary boiler). NG can be transformed into electricity more efficiently in a combined cycle (up to 50-55\%) power plant. This higher efficiency will contribute to improved environmental performance and, in the absence of subsidies, higher revenues.

Acknowledgements Thanks are due to MINECO for funding under Program INNPACTO (IPT-440000-2010-004) and to The European Commission for funding under FP7-ENERGY-2012-1 CP 308912.

\section{References}

AENOR (2006) UNE-EN ISO 14040:2006. Gestión ambiental. Análisis de ciclo de vida. Principios y marco de referencia. (ISO 14040:2006).

Burkhardt III JJ, Heath GA, Turchi CS (2011) Life cycle assessment of a parabolic trough concentrating solar power plant and the impacts of key design alternatives. Environ Sci Technol 45:2457-2464

Burkhardt JJ, Heath G, Cohen E (2012) Life Cycle Greenhouse Gas Emissions of Trough and Tower Concentrating Solar Power Electricity Generation. J Ind Ecol 16:S93-S109.

CORES Corporación de Reservas Estratégicas de productos Petrolíferos (2013).Boletín Estadístico de Hidrocarburos

Davidsson S, Hook M, Wall G (2012) A review of life cycle assessments on wind energy systems. Int J Life Cycle Assess 17:729-742

Emmenegger MF, Stucki M, Hermle S (2012) LCA of energetic biomass utilization: actual projects and new developments-April 23, 2012, Berne, Switzerland. Int J Life Cycle Assess 17:1142-1147

Giostri A, Binotti M, Astolfi M, Silva P, Macchi E, Manzolini G (2012) Comparison of different solar plants based on parabolic trough technology. Sol Energ 86:1208-1221

Goedkoop M, Heijungs R, Huijbregts M, De Schryver, A, Struijs J, van Zelm R (2009) ReCiPe 2008. A life cycle impact assessment method which comprises harmonised category indicators at the midpoint and the endpoint level. First edition.

IEA. 2012. World Energy Outlook 2012, International Energy Agency, ISBN 978-92-64-18084-0 
Jäger-Waldau A, Szabó M, Scarlat N, Monforti-Ferrario F (2011) Renewable electricity in Europe. Renew Sustain Energ Rev 15:3703-3716

Kannan R, Leong KC, Osman R, Ho HK, Tso CP (2005) Gas fired combined cycle plant in Singapore: energy use, GWP and cost — a life cycle approach. Energy Conversion and Management 46:2145-2157

Lechon Y, de la Rua C, Saez R (2008) Life cycle environmental impacts of electricity production by solarthermal power plants in Spain. J Sol Energ-T ASME 130:021012

MINETUR (2012) La energía en España 2011. Ministerio de Industria, Energía y Turismo.

MMA Ministerio de Medio Ambiente (2009) Spanish National Plan for Management of Construction and Demolition Waste (Plan nacional de residuos de construcción y demolición) (2008-2015), integrated in Plan Nacional Integrado de Residuos (PNIR) (BOE 26 Febrero 2009).

NREL (2013) Concentrating Solar Power projects, produced and updated by National Renewable Energy Laboratory (www.nrel.gov/csp/solarpaces/), information accessed in March 2013.

Palgrave R. (2008) Innovation in CSP, Renewable Energy Focus, 9(6), 44-49

Odeh NA, Cockerill TT (2008) Life cycle GHG assessment of fossil fuel power plants with carbon capture and storage. Energy Policy 36:367-380

Oró E, Gil A, de Gracia A, Boer D, Cabeza LF (2012) Comparative life cycle assessment of thermal energy storage systems for solar power plants. Renewable Energy 44:166-173

Piemonte V, Falco MD, Tarquini P, Giaconia A (2011) Life Cycle Assessment of a high temperature molten salt concentrated solar power plant. Sol Energ 85:1101-1108

Protermosolar (2013) Mapa de la Industria Solar Termoélectrica en España. In: . Protermosolar. www.protermosolar.com/mapa.html. Accessed March 2013

RD (2007) Real Decreto 661/2007, de 25 de mayo, por el que se regula la actividad de producción de energía eléctrica en régimen especial. BOE-A-2007-10556

Su Xing, Zhang Xu, Gao Jun (2008) Inventory analysis of LCA on steel- and concrete-construction office buildings. Energ Build 40:1188-93

Suwanit W, Gheewala SH (2011) Life cycle assessment of mini-hydropower plants in Thailand. Int J Life Cycle Assess 16:849-858

Turconi R, Boldrin A, Astrup T (2013) Life cycle assessment (LCA) of electricity generation technologies: Overview, comparability and limitations. Renewable and Sustainable Energy Reviews 28:555-565

Varun, Bhat IK, Prakash R (2009) LCA of renewable energy for electricity generation systems-A review. Renew Sustain Energ Rev 13:1067-1073 